BMJ Open Ophthalmology

\section{Epithelial ingrowth following laser in situ keratomileusis (LASIK): prevalence, risk factors, management and visual outcomes}

To cite: Ting DSJ, Srinivasan S, Danjoux J-P. Epithelial ingrowth following laser in situ keratomileusis (LASIK): prevalence, risk factors, management and visual outcomes. BMJ Open Ophthalmology 2018;3:e000133. doi:10.1136/ bmjophth-2017-000133

Received 27 November 2017 Revised 3 February 2018 Accepted 2 March 2018
Check for updates

${ }^{1}$ Sunderland Eye Infirmary, Sunderland, UK

2Department of Ophthalmology, University Hospital Ayr, Ayr, UK ${ }^{3}$ Faculty of Medicine, University of Glasgow, Glasgow, UK

Correspondence to Sathish Srinivasan; sathish. srinivasan@gmail.com

\section{ABSTRACT}

The number of laser in situ keratomileusis (LASIK) procedures is continuing to rise. Since its first application for correcting simple refractive errors over 25 years ago, the role of LASIK has extended to treat other conditions, including postkeratoplasty astigmatism/ ametropia, postcataract surgery refractive error and presbyopia, among others. The long-term effectiveness, predictability and safety have been well established by many large studies. However, due to the creation of a potential interface between the flap and the underlying stroma, interface complications such as infectious keratitis, diffuse lamellar keratitis and epithelial ingrowth may occur. Post-LASIK epithelial ingrowth (PLEI) is an uncommon complication that usually arises during the early postoperative period. The reported incidence of PLEI ranged from $0 \%-3.9 \%$ in primary treatment to $10 \%-20 \%$ in retreatment cases. It can cause a wide spectrum of clinical presentations, ranging from asymptomatic interface changes to severe visual impairment and flap melt requiring keratoplasty. PLEl can usually be treated with mechanical debridement of the affected interface; however, additional interventions, such as alcohol, mitomycin C, fibrin glue, ocular hydrogel sealant, neodymium:yttriumaluminum garnet laser and amniotic membrane graft, may be required for recurrent or refractory cases. The aims of this review are to determine the prevalence and risk factors of PLEl; to describe its pathogenesis and clinical features and to summarise the therapeutic armamentarium and the visual outcome of PLEI.

\section{INTRODUCTION}

The history of modern-day laser in situ keratomileusis (LASIK) dates back to 1985 when Peyman first introduced the concept of performing laser ablation under a corneal flap. ${ }^{1}$ In 1990, Pallikaris et $a l^{2}$ performed the first LASIK procedure in a rabbit model using a modified microkeratome for corneal flap creation coupled with excimer laser. To date, LASIK remains the most widely performed laser refractive surgery worldwide, with over 1.2 million LASIK surgeries being performed annually in the USA and Europe."

Since its introduction, the role of LASIK has expanded from the initial correction of simple refractive errors to other clinical and refractive indications, including the management of postkeratoplasty astigmatism/ ametropia, postcataract surgery refractive error and presbyopia, among others. ${ }^{4-7}$ The long-term effectiveness, predictability and safety of LASIK have been well established by many long-term studies. ${ }^{89}$ A recent systematic review of LASIK in 67893 eyes reported excellent visual and refractive outcomes with very high patient satisfaction following modern LASIK surgery; $99.5 \%$ of patients achieved uncorrected distance visual acuity of $6 / 12$ or better and $98.6 \%$ of patients achieved spherical equivalent refraction within \pm 1 .0 dioptre (D) of target refraction. ${ }^{10}$

Nonetheless, the creation of an interface between the flap and the underlying corneal stroma can lead to flap-related and flap-stromal interface complications such as flap dislocation, infectious keratitis, diffuse lamellar keratitis and epithelial ingrowth (EI). Post-LASIK epithelial ingrowth (PLEI) is a rare complication that is characterised by the ingrowth of corneal epithelium at the interface between the flap and stromal bed following LASIK, leading to a range of symptoms and signs. In view of its low prevalence, the experience of treating EI is largely based on anecdotal case reports and small case series. The aims of this review are threefold: first, to determine the prevalence and risk factors of PLEI; second, to describe the pathogenesis and clinical features of EI and third, to summarise the therapeutic armamentarium and the visual outcome of PLEI

\section{PREVALENCE OF EPITHELIAL INGROWTH FOLLOWING LASIK AND OTHER TYPES OF SURGERY}

The prevalence of EI following primary LASIK is very low, estimated between $0 \%$ and $3.9 \% .^{11-15}$ However, the risk of EI is significantly increased in various clinical circumstances, especially when the flap is lifted for retreatment (up to $10 \%-20 \%$ ). ${ }^{16-18}$ 
Box 1 Modifiable and non-modifiable risk factors of epithelial ingrowth following LASIK

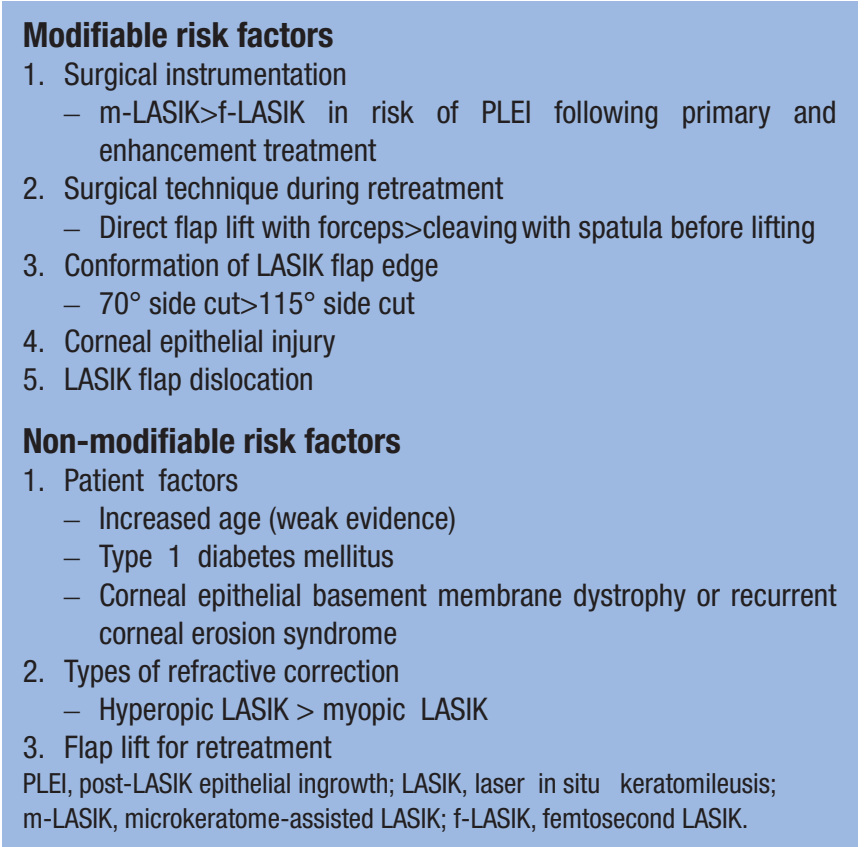

EI has also been rarely reported following trauma and other types of ocular surgery, including penetrating trauma, keratoplasty, cataract and pterygium surgery. ${ }^{19-21}$ Such manifestation is due to the inadvertent introduction of corneal epithelial cells into the intraocular environment, resulting in proliferation of epithelial cells on the surface of intraocular structures such as posterior cornea, anterior chamber angle, ciliary body, iris and lens capsule.

\section{RISK FACTORS OF POST-LASIK EPITHELIAL INGROWTH}

Although the risk of PLEI is low, clinical management can be very challenging in some cases. The risk factors for PLEI are summarised in box 1. A thorough understanding of these risk factors enables better preoperative patient counselling and risk assessment.

\section{Modifiable factors}

Several modifiable factors of PLEI have been described in the literature; these include surgical instrumentation, retreatment technique and conformation of LASIK flap hinge.

\section{Surgical instrumentation}

Flap creation by femtosecond laser or microkeratome represents one of the major steps in LASIK surgery. Some studies have suggested that the instruments used during flap creation could influence the risk of PLEI. ${ }^{182223}$ Letko et $a l^{18}$ observed that the risk of EI following LASIK flaplift for retreatment was significantly lower in patients who were initially treated with femtosecond LASIK (f-LASIK; $1.4 \%)$ as compared with microkeratome-assisted LASIK (m-LASIK; 8.3\%). In another study of 6415 eyes that underwent f-LASIK, the risk of PLEI was reported to be as low as $0.03 \% .{ }^{23}$ It was postulated that the lower incidence of PLEI following f-LASIK was attributed to the geometry of the flap edge and the lower risk of peripheral trauma at the flap edge.

\section{Surgical technique during LASIK retreatment}

Although the long-term efficacy and stability of LASIK surgery have been reported in the published literature, retreatment is occasionally required in some cases due to regression or inadequacy of the treatment effect. ${ }^{24} 25$ Flap lift for retreatment is a well-recognised risk factor for PLEI. Nonetheless, Chan and Boxer Wachler ${ }^{26}$ observed that using a Pinelli spatula to cleave the circumference of the flap edge before lifting the flap could significantly reduce the risk of PLEI when compared with direct flap lifting using forceps. It was suggested that the use of spatula reduced the risk of trauma to the corneal epithelium at the flap edge. On the other hand, the risk of EI associated with LASIK retreatment could be eliminated by employing photorefractive keratectomy over the previous LASIK flap as a retreatment strategy, obviating the need of flap lifting for retreatment. ${ }^{16}$

\section{Conformation of LASIK flap edge}

The conformation of LASIK flap edge may also have an effect on the risk of PLEI. In a rabbit model, Jhanji et $a l^{27}$ reported that PLEI was more frequently observed in flaps with $70^{\circ}$ (conventional) side cuts compared with flaps with $115^{\circ}$ (inverted) side cuts. In addition, corneas with $70^{\circ}$ side cuts showed significantly increased apoptotic cells compared with the inverted side-cuts corneas. Asano-Kato $e t a t^{8}$ similarly reported a greater incidence of PLEI using MK-2000 microkeratome (Nidek, Aichi, Japan) compared with LSK-One microkeratome (Moria, Antony, France) due to the difference in flap edges.

\section{Corneal epithelial injury}

Asano-Kato $e t a l^{28}$ and Jabbur $e t a l^{29}$ have reported that intraoperative epithelial injury/defect is a risk factor of PLEI. Similarly, Wang and Maloney ${ }^{15}$ observed that $33 \%$ of their patients who had a postoperative epithelial defect subsequently developed PLEI. They observed that patients with epithelial basement membrane dystrophy had a higher recurrence rate of PLEI, requiring multiple surgical debridement. They proposed that the epithelial defect resulted in flap hydration/oedema, ultimately leading to a poor adhesion of the flap-stromal interface with PLEI.

\section{LASIK flap dislocation}

LASIK flap dislocation is a recognised risk for PLEI. ${ }^{30}{ }^{31} \mathrm{It}$ shares the similar principle with cases of flap-lift retreatment where the corneal epithelial cells at the flap-host junction are given access to the flap-stromal interface due to poor adhesion/dislocation of the flap edge. Therefore, the development of late-onset PLEI should raise the 
suspicion of occult dislocation of the LASIK flap and a history of trauma should be elicited. ${ }^{31}$

\section{Non-modifiable factors}

Several non-modifiable factors have also been described in the literature. These include patient demographics, preoperative refractive errors and primary and retreatment procedures.

\section{Patient factors}

One study of 30 eyes suggested that older age might increase the risk of PLEI. ${ }^{26}$ However, this was not observed in a larger study that included 4500 LASIK eyes. ${ }^{12}$ Similarly, there is no clear gender or race predilection for PLEI. ${ }^{12}$ In terms of ocular factors, various studies have demonstrated the positive association between PLEI and corneal epithelial basement membrane dystrophy. ${ }^{15} 29$ Systemic factor such as type 1 diabetes mellitus may also increase the risk of PLEI. ${ }^{29}$

\section{Hyperopic versus myopic LASIK}

Hyperopic LASIK has been associated with a higher risk of PLEI as compared with myopic LASIK. ${ }^{112}$ In a retrospective study of 1000 m-LASIK procedures, Mohamed et al ${ }^{11}$ had observed a significant higher risk of PLEI in patients who were undergoing hyperopic LASIK as opposed to myopic LASIK. The incidence of PLEI following hyperopic LASIK was seven times higher than myopic LASIK (23\% vs $3 \%$ ) and the increased risk was observed in both primary (17\% vs $3 \%)$ and enhancement treatment (43\% vs 7\%). ${ }^{11}$ This may be related to the fact that laser ablation is applied at the mid-periphery of the cornea in hyperopic LASIK as opposed to the central of the cornea in myopic LASIK. The conformational change in the mid-periphery of the cornea (closer to the flap edge) can potentially affect the flap-stromal adhesion, increasing the risk of PLEI.

\section{Primary versus retreatment LASIK}

Although LASIK surgery has a well-established long-term effectiveness and refractive stability, approximately up to $10 \%-14 \%$ of the patients may undergo retreatment/ enhancement at some stage following their initial LASIK surgery. ${ }^{153-35}$ LASIK flap lifts for retreatment increases the risk for EI with the reported incidence ranging from $1.7 \%$ to $23.3 \%$ when compared with $0 \%$ to $3.9 \%$ for primary treatments. ${ }^{11-1833}$ Moreover, flap-lift retreatment performed three or more years after primary LASIK carry a higher risk of clinically significant PLEI compared with retreatments with flap lifts done earlier. ${ }^{12}$

\section{PATHOGENESIS OF POST-LASIK EPITHELIAL INGROWTH AND CORNEAL WOUND HEALING}

The pathogenesis of PLEI is attributed to two underlying mechanisms. Implantation of the corneal epithelial cells during the flap creation, resulting in epithelial nests away from the flap edge. These epithelial cells usually have minimal proliferative ability due to limited nourishment from the ocular surface environment and may remain asymptomatic. Second, PLEI may be a consequence of corneal epithelial cells migrating from the flap edge towards the flap-stromal interface due to poor flap adhesion, flap dislocation or presence of foreign bodies (eg, blood, cell infiltrate, ointment, etc) at the flap-stromal interface. ${ }^{1528}$ In this instance, the poorly attached or dislocated flap allows the invasion of epithelial cells into the interface. Subsequently, these invaded cells lift up the edge of the flap, causing pooling of the fluorescein. ${ }^{15}$ Proliferation of the invaded epithelial cells culminates in the formation of a fistula, resulting in progressive PLEI. Interestingly, the histopathological findings of PLEI differs in early and late stages according to a Japanese study. ${ }^{36}$ It was shown that early PLEI comprised multilayered squamous epithelium resembling normal corneal epithelium, whereas late PLEI consisted of clumps containing amorphous materials with little cellular elements, potentially reflecting different proliferative activity of EI at different stages. ${ }^{36}$

Various studies have shown that the corneal wound healing following LASIK primarily occurs at the periphery of the LASIK flap-corneal stromal junction. ${ }^{37} 38$ This healing phenomenon explains the late onset of LASIK flap dislocation, even over a decade after the initial LASIK surgery. ${ }^{31}$ Therefore, the development of lateonset of PLEI in a patient with previous LASIK surgery should raise the suspicion of occult traumatic dislocation of LASIK flap.

\section{CLASSIFICATION}

Based on the location, clinical features and severity, PLEI can be categorised into four grades using the Prosbt/ Machatclassification (table 2). ${ }^{39}$ This classification serves as a useful aid for consistent and standardised grading/ assessment and provides guidance on the treatment strategies.

\section{CLINICAL FEATURES AND ASSESSMENT}

A wide spectrum of clinical presentations has been reported in the literature; these range from asymptomatic corneal changes to severe visual impairment and flap melt requiring keratoplasty. The onset of PLEI usually takes place within a month following primary or enhancement LASIK. ${ }^{15}$ However, many patients are asymptomatic from PLEI, explaining the wide range of time interval between the initial LASIK surgery and presentation of PLEI (0.5-108 months). ${ }^{40}$ Rapuano reported in his study that as many as $64 \%$ of the eyes affected by PLEI did not require any intervention. ${ }^{40}$ These patients usually have PLEI within $2 \mathrm{~mm}$ from the flap edge (Prosbt/Machat grade 1) with no visual symptoms. In some cases, patients may experience foreign body sensation and glare due to ocular surface irregularity secondary to PLEI.

In terms of clinical features, Wang and Maloney ${ }^{15}$ have described four key clinical signs/characteristics that could aid in the diagnosis of PLEI. These include epithelial Pearls/nest in the interface (figure 1A), fluorescein pooling at the edge of the flap (due to elevation of flap 


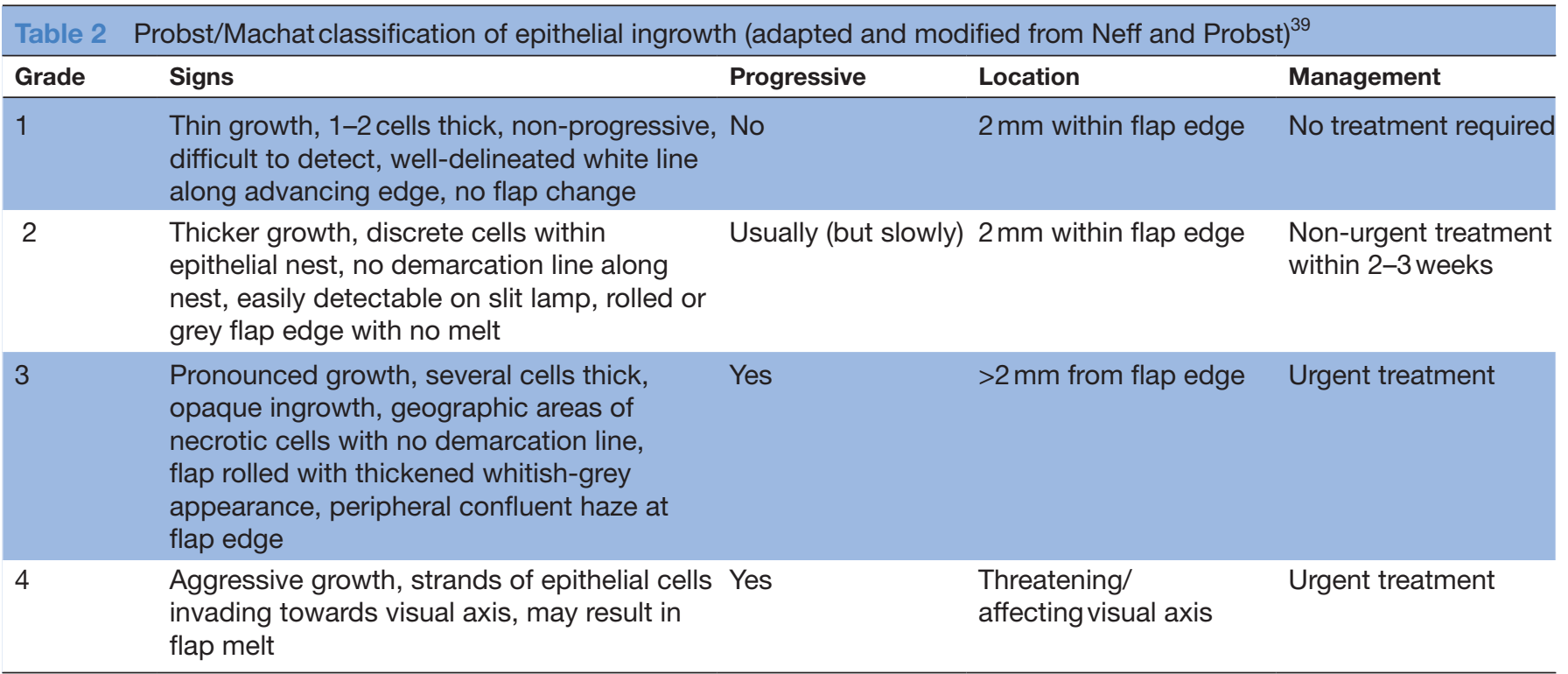

edge by underlying invading epithelial cells), white fibrotic demarcation line and keratolysis/melting of the flap edge. Other signs include diffuse opaque epithelial ingrowth (figure 1B), rolled up flap edge with thickened whitish-grey appearance, staining channels and peripheral confluent haze.

In addition to slit lamp examination, other investigative tools can be used to assist in the assessment and monitoring of PLEI. Anterior segment optical coherence tomography serves as a useful investigation in detecting subtle PLEI changes that are not readily evident on slit lamp examination (figure 1C-D). Corneal topography/ tomographycan be used to assess the PLEI-induced refractive changes and ocular surface irregularity. In addition, corneal densitometry using Scheimpflug tomography can be used to provide objective quantification and monitoring of the severity and progression of EI. ${ }^{41}$

\section{TREATMENT MODALITIES}

The indications for medical or surgical treatment of PLEI are largely guided by the patient's symptoms, location and severity of the PLEI, and the presence of any associated pathology such as flap dislocation/dehiscence. In most cases, PLEI can be surgically removed with mechanical debridement of the interface; however, clinically significant recurrence may be as high as $36 \%$ after such treatment. ${ }^{42}$ The visual outcomes, recurrence rate and complication of various treatment modalities of PLEI are summarised in table 3. ${ }^{1315} 4042-60$

The most common treatment strategy for PLEI is mechanical debridement of the EI from the flap-stromal interface and from the inner side of the flap followed by careful repositioning of the flap and avoidance of any intraoperative/postoperative epithelial trauma. ${ }^{15} \quad 40 \quad 42$ Flap suturing, fibrin glue and ocular hydrogel sealant at the flap edge have been proposed to facilitate secured flap adhesion. ${ }^{13} 404346-53$ In refractory cases, various adjunctive therapies can be used to help eradicate PLEI. Amniotic membrane graft (AMG) may be used in cases of PLEI associated with flap injury or melting. ${ }^{54-56}$ In addition, the use of non-invasive neodymium:yttrium aluminum garnet (Nd:YAG) laser has also been reported as a novel technique for treating PLEI. ${ }^{58-60}$

\section{Recommendation}

Based on the available evidence in the literature, we recommend simple mechanical debridement in the first presentation of PLEI. Mechanical debridement can be performed using non-shredding spears, spatula or other appropriate instruments. A bandage contact lens should be placed to protect the flap and reduce the risk of flap dehiscence/dislocation, ${ }^{15} 4050$ although there was a small study of 30 eyes reporting an increased risk of PLEI with bandage contact lens use. ${ }^{26}$ All patients should be counselled on the risk of recurrence of EI (0\%-36\%) following the treatment, which may require further debridement. In patients with one or more episodes of recurrent EI, adjunctive therapies need to be administered to reduce further risk of recurrence. Various strategies have been described in the literature but many of the studies are of anecdotal case reports and small case series. Based on the evidence from larger studies ( $\geq 10$ treated eyes), we recommend the use of either flap suturing with 10 ' 0 nylon or fibrin glue to achieve secured flap-stromal adhesion. The recurrence rates following these treatment strategies range between $0 \%-33 \%$ and $0 \%-7.7 \%$, respectively. The low recurrence rate of PLEI following the application of fibrin glue is likely attributed to its inhibitory property on the migration of ocular surface epithelial cells. ${ }^{61}$ In addition, antimetabolite, such as mitomycin C $0.02 \%$, and AMG can be used to treat refractory cases and those associated with flap melt/injury, respectively. For patients who are unable to tolerate surgery, Nd:YAG laser using low energy of $(0.6 \mathrm{~mJ}$ on average) can be applied as an alternative treatment. However, the experience and 


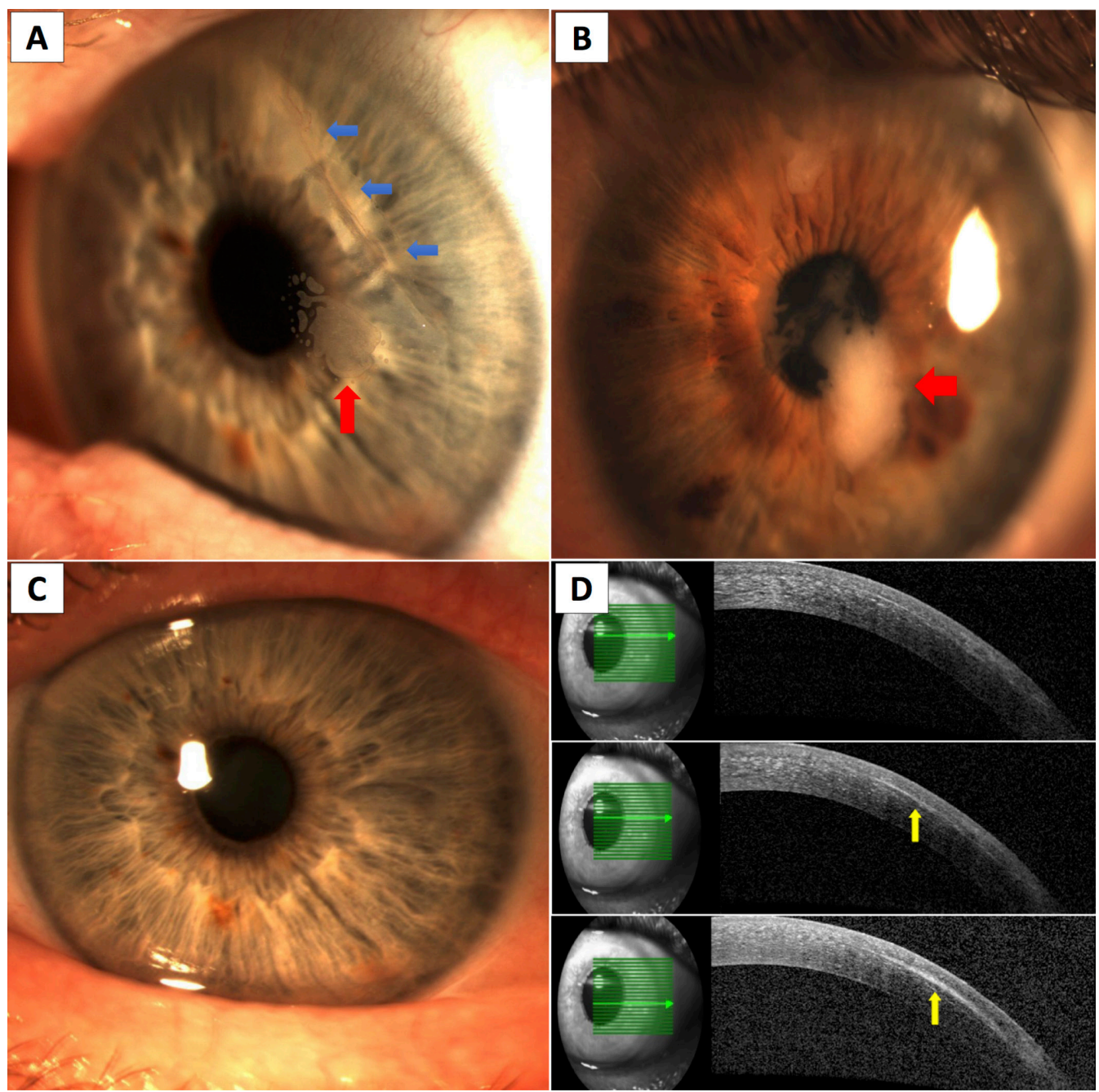

Figure 1 (A) Slit lamp photography showing an area of epithelial nest/ingrowth at the flap-stromal interface (red, up arrow) associated with a dislocated, infolded superior temporal LASIK flap (blue, left arrows). (B) Slit lamp photography showing diffuse opaque epithelial ingrowth (red, left arrows) associated with occult traumatic dislocation of LASIK flap. (C) Slit lamp photography showing an apparently clear cornea after removal of epithelial ingrowth. (D) However, subtle residual epithelial ingrowth (yellow, up arrows) was identified on anterior segment optical coherence tomography (AS-OCT). At 3-month postremoval of epithelial ingrowth, there was a recurrence of epithelial ingrowth (visible on slit lamp examination) at the same area highlighted by the AS-OCT.

evidence is limited to one large case series of 30 eyes and a few case reports, and care needs to be taken during the procedure to avoid any flap complication. In addition, $40 \%$ or more patients require repeat treatment to eliminate the EI completely.

\section{TREATMENT COMPLICATIONS}

The most common complication following the treatment of PLEI is recurrence of EI, usually recurring at the original area of PLEI. Risk factors for recurrence include infectious aetiology of EI, use of microkeratome for primary LASIK, hyperopic LASIK and previous history of recurrence. ${ }^{40}{ }^{42}{ }^{43}$ Based on large case series, the recurrence rate following treatment, depending on the treatment strategy and follow-up duration, ranged between $0 \%$ and $36 \%$ (table 3). Mechanical debridement of both the interface and the inner aspect of the flap followed by the application of fibrin glue appears to have the lowest recurrence rate of PLEI as compared with other treatment modalities. Other uncommon complications such as diffuse lamellar keratitis and flap melt (up to $80 \%$ of the flap) have been reported following the use of highly concentrated ethanol (50\%-100\%) at the flap-stromal interface. ${ }^{62}$ Non-invasive Nd:YAG laser treatment of PLEI may also lead to localised flap melt, flap surface breakthrough and inadvertent creation of new channel at the flap edge, resulting in new areas of EI. ${ }^{63} 64$

\section{VISUAL OUTCOME AND PROGNOSIS}

The visual outcome of PLEI is largely dependent on the location and the severity of the ingrowth (Probst/ Machatclassification). However, PLEI is often not graded according to the classification, but by the need for intervention, in many studies (eg, whether PLEI is clinically significant to warrant removal). Therefore, 
Table 3 The summary of visual outcomes, recurrence rate and complications of various treatment modalities for postlaser in situ keratomileusis (LASIK) epithelial ingrowth

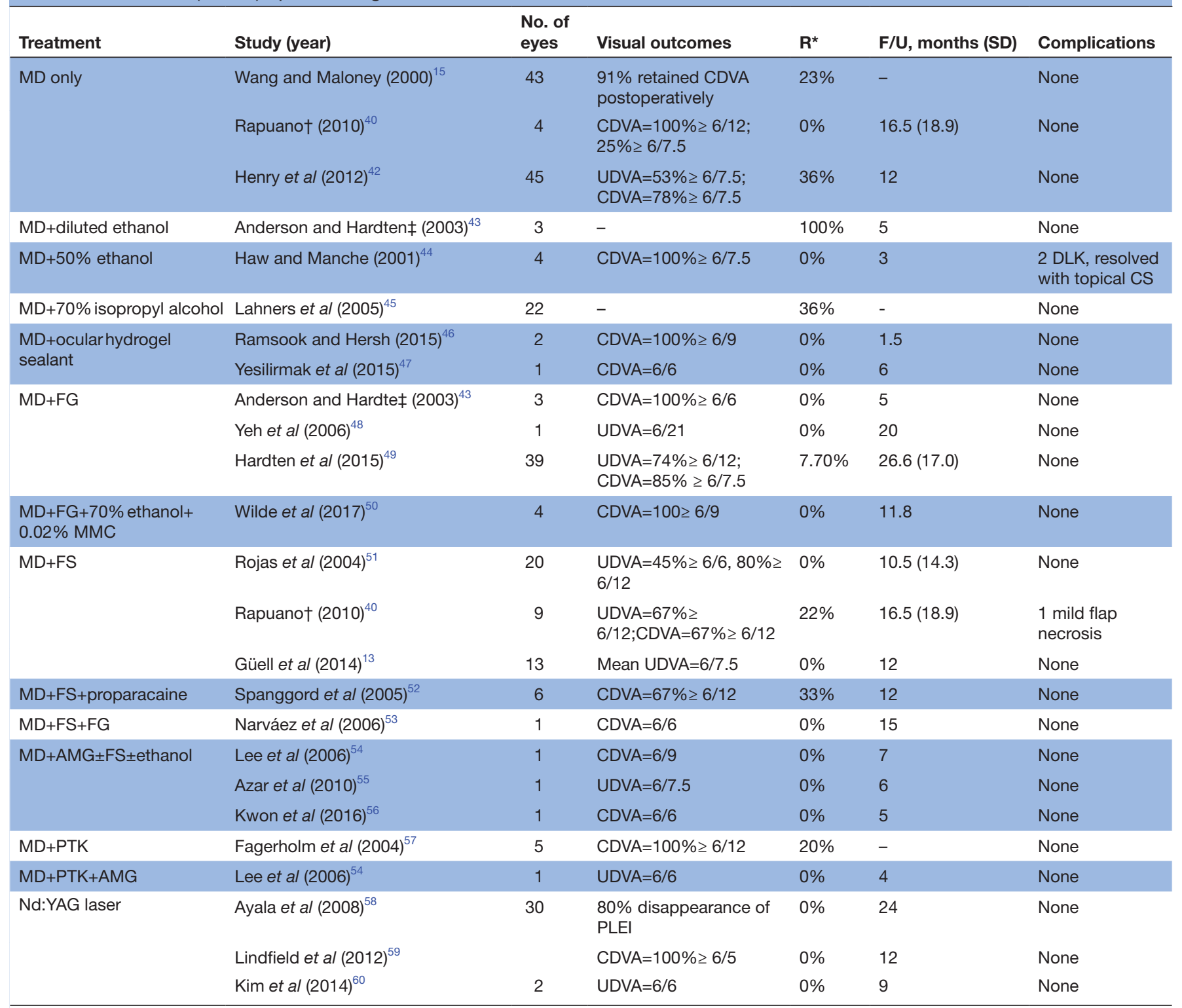

The majority of studies that specifically evaluated the treatment outcome of significant post-LASIK epithelial ingrowth (PLEI) are included in this table. ${ }^{*}$ Recurrence refers to rate of significant recurrence of epithelial ingrowth following the initial treatment.

†Rapuano reported 13 eyes of PLEl that underwent mechanical debridement, with 9 eyes being treated with additional flap suturing.

‡This study included three patients who were all initially treated with MD and diluted ethanol. However, all of them had a significant recurrence of epithelial ingrowth which required a further MD and application of fibrin glue.

AMG, amniotic membrane graft; CDVA, corrected distance visual acuity; CS, corticosteroids; DLK, diffuse lamellar keratitis; FG, fibrin glue; FS, flap suturing; MD, mechanical debridement; MMC, mitomycin C; Nd:YAG, neodymium: yttrium aluminum garnet; PTK, phototherapeutic keratectomy; UDVA, uncorrected distance visual acuity.

by definition, patients who require surgical/procedural intervention have PLEI of grade 2 or more. In addition, the visual outcome may be confounded by publication bias (eg, only studies with good visual outcome are published).

Patients with grade 1 PLEI (within $2 \mathrm{~mm}$ of flap edge without any problem with the flap edge) are usually asymptomatic with unaffected vision. Rapuano has reported that $64 \%$ of his patients with PLEI were managed with simple observation. ${ }^{40}$ In grade 2 and grade 3 PLEI, good visual outcome is normally retained following appropriate treatment. Based on larger studies ( $\geq 10$ treated eyes), patients with PLEI usually achieved uncorrected distance visual acuity of $\geq 6 / 12$ (in $74 \%-80 \%$ cases) and $\geq 6 / 7.5$ (in $45 \%-53 \%$ cases), and corrected distance visual acuity of $\geq 6 / 12$ (in $77 \%-91 \%$ cases) and $\geq 6 / 7.5$ (in $78 \%-85 \%$ cases) following treatment. Central involvement of the cornea serves as the poor visual prognostic factor for PLEI. ${ }^{42}$ In extreme cases of flap melt (grade 4), significant flap-stromal interface scarring or aggressive PLEI, flap amputation or penetrating keratoplasty may be required to improve 
the vision and eradicate persistent PLEI. ${ }^{65-67}$ On the other hand, a rare case of spontaneous resolution of PLEI has been reported in the literature. ${ }^{68}$

\section{CONCLUSION}

With the continuing rise of LASIK procedures, it is important for all ophthalmologists to become competent in recognising and/or managing post-LASIK complications, including PLEI. Understanding of both modifiable and non-modifiable risk factors helps reduce the incidence of PLEI and also enables better patient counselling preoperatively. When appropriately managed, good visual prognosis is usually achieved in patients with PLEI. However, additional measures and interventions may be required in aggressive or refractory PLEI cases in order to achieve complete and permanent eradication of the disease.

\section{METHOD OF LITERATURE SEARCH}

A literature search in PubMed electronic database was conducted to identify all articles concerning EI following LASIK. Abstracts were further reviewed and the reference lists were hand-searched to ensure complete inclusion of all relevant articles. Only articles published in English were included. Certain keywords, including epithelial ingrowth, epithelial downgrowth, laser in situ keratomileusis and LASIK, were used during the literature search.

Contributors DSJT is involved in the conception and planning of the study, review of the literature, manuscript drafting and final approval of the manuscript. SS is involved in the review of the literature, critical appraisal and final approval of the manuscript. J-PD is involved in the review of the literature, critical appraisal and final approval of the manuscript.

Funding This research received no specific grant from any funding agency in the public, commercial or not-for-profit sectors.

Competing interests None declared.

Patient consent Detail has been removed from this case description/these case descriptions to ensure anonymity. The editors and reviewers have seen the detailed information available and are satisfied that the information backs up the case the authors are making.

Provenance and peer review Not commissioned; externally peer reviewed.

Open Access This is an Open Access article distributed in accordance with the Creative Commons Attribution Non Commercial (CC BY-NC 4.0) license, which permits others to distribute, remix, adapt, build upon this work non-commercially, and license their derivative works on different terms, provided the original work is properly cited and the use is non-commercial. See: http://creativecommons.org/ licenses/by-nc/4.0/

(C) Article author(s) (or their employer(s) unless otherwise stated in the text of the article) 2018. All rights reserved. No commercial use is permitted unless otherwise expressly granted.

\section{REFERENCES}

1. Peyman GA. Method for modifying corneal curvature. US patent 4840175. 1989 http://patft.uspto.gov/netacgi/nph-Parser?Sect1= PTO1\&Sect2 $=$ HITOFF \& $d=P A L L \& p=1 \& u=\% 2 F n e t a h t m 1 \% 2 F P T O \%$ 2Fsrchnum.htm\& $r=1 \& f=G \& l=50 \& s 1=4,840,175 . P N . \& O S=P N / 4,840$, 175\&RS=PN/4,840,175 (accessed on 15 Sep 2017).

2. Pallikaris IG, Papatzanaki ME, Stathi EZ, et al. Laser in situ keratomileusis. Lasers Surg Med 1990;10:463-8.
3. Statista. Number of LASIK surgeries in Europe from 2004 to 2020 (in thousands). https://www.statista.com/statistics/278481/number-oflasik-surgeries-in-the-us/ (accessed on 15 Sep 2017).

4. Kuryan J, Channa P. Refractive surgery after corneal transplant. Curr Opin Ophthalmol 2010;21:1-64.

5. Acar BT, Utine CA, Acar S, et al. Laser in situ keratomileusis to manage refractive errors after deep anterior lamellar keratoplasty. $J$ Cataract Refract Surg 2012;38:1020-7.

6. Kim P, Briganti EM, Sutton GL, et al. Laser in situ keratomileusis for refractive error after cataract surgery. J Cataract Refract Surg 2005;31:979-86.

7. Chan TC, Kwok PS, Jhanji V, et al. Presbyopic correction using monocular Bi-aspheric Ablation Profile (PresbyMAX) in Hyperopic Eyes: 1-Year Outcomes. J Refract Surg 2017;33:37-43.

8. Dirani M, Couper T, Yau J, et al. Long-term refractive outcomes and stability after excimer laser surgery for myopia. $J$ Cataract Refract Surg 2010;36:1709-17.

9. Alió JL, Ortiz D, Muftuoglu O, et al. Ten years after photorefractive keratectomy (PRK) and laser in situ keratomileusis (LASIK) for moderate to high myopia (control-matched study). Br J Ophthalmol 2009;93:1313-8.

10. Sandoval HP, Donnenfeld ED, Kohnen T, et al. Modern laser in situ keratomileusis outcomes. J Cataract Refract Surg 2016;42:1224-34.

11. Mohamed TA, Hoffman RS, Fine IH, et al. Post-laser assisted in situ keratomileusis epithelial ingrowth and its relation to pretreatment refractive error. Cornea 2011;30:550-2.

12. Caster AI, Friess DW, Schwendeman FJ. Incidence of epithelial ingrowth in primary and retreatment laser in situ keratomileusis. $J$ Cataract Refract Surg 2010;36:97-101.

13. Güell JL, Verdaguer P, Mateu-Figueras G, et al. Epithelial ingrowth after LASIK: visual and refractive results after cleaning the interface and suturing the lenticule. Cornea 2014;33:1046-50.

14. Lui MM, Silas MA, Fugishima H. Complications of photorefractive keratectomy and laser in situ keratomileusis. J Refract Surg 2003;19:S247-9.

15. Wang MY, Maloney RK. Epithelial ingrowth after laser in situ keratomileusis. Am J Ophthalmol 2000;129:746-51.

16. Ortega-Usobiaga J, Llovet-Osuna F, Katz T, et al. Comparison of 5468 retreatments after laser in situ keratomileusis by lifting the flap or performing photorefractive keratectomy on the flap. Arch Soc Esp Oftalmol 2018:93:30161-2.

17. Schallhorn SC, Venter JA, Hannan SJ, et al. Flap lift and photorefractive keratectomy enhancements after primary laser in situ keratomileusis using a wavefront-guided ablation profile: Refractive and visual outcomes. J Cataract Refract Surg 2015;41:2501-12.

18. Letko $E$, Price MO, Price FW. Influence of original flap creation method on incidence of epithelial ingrowth after LASIK retreatment. $J$ Refract Surg 2009;25:1039-41.

19. Dalal RR, Raber I, Dunn SP, et al. Epithelial Ingrowth Following Endothelial Keratoplasty. Cornea 2016;35:465-70.

20. Ghosh S, Mukhopadhyay S. Epithelial ingrowth following surgery of recurrent pterygium. Int Ophthalmol 2008;28:63-5.

21. Küchle M, Green WR. Epithelial ingrowth: a study of 207 histopathologically proven cases. Ger J Ophthalmol 1996;5:211-23.

22. Vaddavalli PK, Yoo SH, Diakonis VF, et al. Femtosecond laserassisted retreatment for residual refractive errors after laser in situ keratomileusis. J Cataract Refract Surg 2013;39:1241-7.

23. Kamburoğlu G, Ertan A. Epithelial ingrowth after femtosecond laserassisted in situ keratomileusis. Cornea 2008;27:1122-5.

24. Pokroy R, Mimouni M, Sela T, et al. Myopic laser in situ keratomileusis retreatment: Incidence and associations. J Cataract Refract Surg 2016:42:1408-14.

25. Santhiago MR, Smadja D, Zaleski K, et al. Flap relift for retreatment after femtosecond laser-assisted LASIK. J Refract Surg 2012;28:482-7.

26. Chan CC, Boxer Wachler BS. Comparison of the effects of LASIK retreatment techniques on epithelial ingrowth rates. Ophthalmology 2007;114:640-2.

27. Jhanji V, Chan TC, Li WY, et al. Conventional Versus Inverted Sidecut Flaps for Femtosecond Laser-Assisted LASIK: Laboratory and Clinical Evaluation. J Refract Surg 2017;33:96-103.

28. Asano-Kato N, Toda I, Hori-Komai Y, et al. Epithelial ingrowth after laser in situ keratomileusis: clinical features and possible mechanisms. Am J Ophthalmol 2002;134:801-7.

29. Jabbur NS, Chicani CF, Kuo IC, et al. Risk factors in interface epithelialization after laser in situ keratomileusis. J Refract Surg 2004;20:343-8

30. Xiao J, Jiang $\mathrm{C}$, Zhang $\mathrm{M}$, et al. When case report became case series: 45 cases of late traumatic flap complications after laserassisted in situ keratomileusis and review of Chinese literature. $\mathrm{Br} \mathrm{J}$ Ophthalmol 2014;98:1282-6. 
31. Holt DG, Sikder S, Mifflin MD. Surgical management of traumatic LASIK flap dislocation with macrostriae and epithelial ingrowth 14 years postoperatively. J Cataract Refract Surg 2012;38:357-61.

32. Vesaluoma MH, Petroll WM, Pérez-Santonja JJ, et al. Laser in situ keratomileusis flap margin: wound healing and complications imaged by in vivo confocal microscopy. Am J Ophthalmol 2000;130:564-73.

33. McAlinden C, Moore JE. Retreatment of residual refractive errors with flap lift laser in situ keratomileusis. Eur J Ophthalmol 2011;21:5-11.

34. Netto MV, Wilson SE. Flap lift for LASIK retreatment in eyes with myopia. Ophthalmology 2004;111:1362-7.

35. Hersh PS, Fry KL, Bishop DS. Incidence and associations of retreatment after LASIK. Ophthalmology 2003;110:748-54.

36. Asano-Kato N, Toda I, Hori-Komai Y, et al. Histopathological findings of epithelial ingrowth after laser in situ keratomileusis. Cornea 2005;24:130-4.

37. Pérez-Santonja JJ, Linna TU, Tervo KM, et al. Corneal wound healing after laser in situ keratomileusis in rabbits. J Refract Surg 1998;14:602-9.

38. Wachtlin J, Langenbeck K, Schründer S, et al. Immunohistology of corneal wound healing after photorefractive keratectomy and laser in situ keratomileusis. wachtlin@ukbf.fu-berlin.de. J Refract Surg 1999;15:451-8.

39. Neff KD, Probst LE. LASIK complications. In: Krachmer JH, Mannis $\mathrm{MJ}$, Holland EJ, eds. Cornea: surgery of the cornea and conjunctiva. 3rd edn. St. Louis, MO: Mosby, 2011:1861-82.

40. Rapuano CJ. Management of epithelial ingrowth after laser in situ keratomileusis on a tertiary care cornea service. Cornea 2010;29:307-13.

41. Adran D, Vaillancourt L, Harissi-Dagher M, et al. Corneal densitometry as a tool to measure epithelial ingrowth after laser in situ keratomileusis. Cornea 2017;36:406-10.

42. Henry CR, Canto AP, Galor A, et al. Epithelial ingrowth after LASIK: clinical characteristics, risk factors, and visual outcomes in patients requiring flap lift. J Refract Surg 2012;28:488-92.

43. Anderson NJ, Hardten DR. Fibrin glue for the prevention of epithelial ingrowth after laser in situ keratomileusis. $J$ Cataract Refract Surg 2003;29:1425-9.

44. Haw WW, Manche EE. Treatment of progressive or recurrent epithelial ingrowth with ethanol following laser in situ keratomileusis. $J$ Refract Surg 2001:17:63-8.

45. Lahners WJ, Hardten DR, Lindstrom RL. Alcohol and mechanical scraping for epithelial ingrowth following laser in situ keratomileusis. $J$ Refract Surg 2005;21:148-51.

46. Ramsook SS, Hersh PS. Use of a hydrogel sealant in epithelial ingrowth removal after laser in situ keratomileusis. J Cataract Refract Surg 2015;41:2768-71.

47. Yesilirmak N, Diakonis VF, Battle JF, et al. Application of a hydrogel ocular sealant to avoid recurrence of epithelial ingrowth after LASIK enhancement. J Refract Surg 2015;31:275-7.

48. Yeh DL, Bushley DM, Kim T. Treatment of traumatic LASIK flap dislocation and epithelial ingrowth with fibrin glue. Am J Ophthalmol 2006;141:960-2.

49. Hardten DR, Fahmy MM, Vora GK, et al. Fibrin adhesive in conjunction with epithelial ingrowth removal after laser in situ keratomileusis: longterm results. J Cataract Refract Surg 2015;41:1400-5.
50. Wilde C, Messina M, Dua HS. Management of recurrent epithelial ingrowth following laser in situ keratomileusis with mechanical debridement, alcohol, mitomycin-C, and fibrin glue. J Cataract Refract Surg 2017;43:980-4.

51. Rojas MC, Lumba JD, Manche EE. Treatment of epithelial ingrowth after laser in situ keratomileusis with mechanical debridement and flap suturing. Arch Ophthalmol 2004:122:997-1001.

52. Spanggord HM, Epstein RJ, Lane HA, et al. Flap suturing with proparacaine for recurrent epithelial ingrowth following laser in situ keratomileusis surgery. J Cataract Refract Surg 2005;31:916-21.

53. Narváez J, Chakrabarty A, Chang K. Treatment of epithelial ingrowth after LASIK enhancement with a combined technique of mechanical debridement, flap suturing, and fibrin glue application. Cornea 2006;25:1115-7.

54. Lee ES, Lee HK, Cristol SM, et al. Amniotic membrane as a biologic pressure patch for treating epithelial ingrowth under a damaged laser in situ keratomileusis flap. $J$ Cataract Refract Surg 2006;32:162-5.

55. Azar G, Doan S, Cochereau I, et al. Management of postLASIK recurrent epithelial ingrowth with flap melting using annular amniotic membrane graft. $J$ Cataract Refract Surg 2010;36:2207-8

56. Kwon KY, Ji YW, Lee J, et al. Inhibition of recurrence of epithelial ingrowth with an amniotic membrane pressure patch to a laser in situ keratomileusis flap with a central stellate laceration: a case report. BMC Ophthalmol 2016;16:111.

57. Fagerholm P, Molander N, Podskochy A, et al. Epithelial ingrowth after LASIK treatment with scraping and phototherapeutic keratectomy. Acta Ophthalmol Scand 2004;82:707-13.

58. Ayala MJ, Alió JL, Mulet ME, et al. Treatment of laser in situ keratomileusis interface epithelial ingrowth with neodymium:yytriumaluminum-garnet laser. Am J Ophthalmol 2008;145:630-4.

59. Lindfield D, Ansari G, Poole T. Nd:YAG laser treatment for epithelial ingrowth after laser refractive surgery. Ophthalmic Surg Lasers Imaging 2012;43:247-9.

60. Kim JM, Goel M, Pathak A. Epithelial ingrowth - Nd:YAG laser approach. Clin Exp Ophthalmol 2014:42:389-90.

61. Yeung AM, Faraj LA, Mclntosh OD, et al. Fibrin glue inhibits migration of ocular surface epithelial cells. Eye 2016;30:1389-94.

62. Vroman DT, Karp CL. Complication from use of alcohol to treat epithelial ingrowth after laser-assisted in situ keratomileusis. Arch Ophthalmol 2001:119:1378-9.

63. Kucukevcilioglu M, Hurmeric V. Localized flap melt after Nd-YAG laser treatment in recurrent post-LASIK epithelial ingrowth. Arq Bras Oftalmol 2015;78:250-1.

64. Lapid-Gortzak R, Hughes JM, Nieuwendaal CP, et al. LASIK flap breakthrough in Nd:YAG laser treatment of epithelial ingrowth. $J$ Refract Surg 2015;31:342-5.

65. Domniz Y, Comaish IF, Lawless MA, et al. Epithelial ingrowth: causes, prevention, and treatment in 5 cases. $J$ Cataract Refract Surg 2001;27:1803-11.

66. Randleman JB, Banning CS, Stulting RD, et al. Persistent epithelial ingrowth. Ophthalmology 2006;113:1468-9.

67. Chhadva P, Cabot F, Galor A, et al. Long-term outcomes of flap amputation after LASIK. J Refract Surg 2016;32:136-7.

68. Zhang R, Jhanji V, Sun L, et al. Spontaneous resolution of delayed epithelial ingrowth after LASIK. Eye Contact Lens 2013;39:400-1. 